\title{
Sixty seconds on ... the RECOVERY trial
}

\author{
Gareth lacobucci
}

The BMJ

\section{What's this?}

The Randomised Evaluation of covid-19 therapy (aka RECOVERY $)^{1}$ is one of the largest national covid-19 clinical trials set up in England. Led by University of Oxford and funded by the government through the National Institute for Health Research, this major hospital based study is testing the effectiveness of new or existing drugs for treating the virus.

\section{Such as?}

The combination treatment for HIV lopinavir-ritonavir, the steroid dexamethasone, the malaria drug hydroxychloroquine, and the antibiotic azithromycin are all being examined.

\section{Which patients are being studied?}

Adults in England who have been hospitalised for covid-19 (either confirmed by a laboratory test or considered likely by their doctors) are being enrolled.

\section{Is it up and running already?}

Yes. The study was only approved on 11 March 2020. As of 20 April, it had recruited a staggering 6000 patients in 170 NHS hospitals around the UK. It is being described as the largest and fastest growing clinical trial in the world.

\section{Impressive. How did they do it?}

The four UK chief medical officers wrote to all NHS trust leaders asking them to make "every effort" to enrol covid-19 patients in RECOVERY and to other national priority clinical trials. "The results are essential to the future treatment of UK and global patients," the CMOs said.

\section{What is being measured?}

The main study outcomes are death in hospital, discharge, the need for ventilation, and the need for renal replacement therapy. ${ }^{2}$ It also aims to collect additional information on longer term outcomes through review of medical records or linkage to national medical databases such as NHS Digital's Secondary Uses Service.

\section{How is the trial designed?}

All eligible patients are being randomly allocated between several treatment arms, each of which is given alongside the usual standard of care in the hospital. The trial has an "adaptive" design which means it will be able to test new treatments as they become available. Conscious that some hospitals may suddenly be overloaded with cases, the study has been designed to have "the least possible impact on NHS staff."

\section{What does this mean in practice?}

Patient enrolment and randomisation is being done through the internet, and all other trial procedures have been "greatly streamlined," the study protocol says, adding that informed consent is simple and data entry is minimal.

\section{When does it expect to publish findings?}

The study is promising "rapid assessment" of treatments and is aiming to have data available to inform patient treatment by June 2020.

\section{RECOVERY Trial. www.recoverytrial.net.}

2 RECOVERY Trial. Protocol. www.recoverytrial.net/files/recovery-protocol-v3-0-2020-0407.pdf.

RECOVERY Trial. For site staff. www.recoverytrial.net/for-site-staff.

Published by the BMJ Publishing Group Limited. For permission to use (where not already granted under a licence) please go to http://group.bmj.com/group/rights-licensing/ permissions 